\title{
Structuring for high reliability: HR practices and mindful processes in reliability-seeking organizations
}

\author{
TIMOTHY J. VOGUS* AND THERESA M. WELBOURNE \\ University of Michigan Business School, Ann Arbor, Michigan, U.S.A.
}

\begin{abstract}
Summary This paper theoretically and empirically connects the literature on high-reliability organizations (HROs) to a broader set of organizations, which we call reliability-seeking organizations. Unlike HROs, which operate high-hazard technologies, reliability-seeking organizations operate in high-hazard environments. Reliability-seeking organizations are tightly coupled to their unpredictable and complex environments in such a manner that although the human mortality rate is low, the risk of small failures amplifying into organizational mortality is high. To cope with these environments, reliability-seeking organizations organize to remain open and flexible to emerging information and achieve the reliability demanded by their environmentsintensity of innovation. These organizations utilize skilled temporary employees, positive employee relations, and an emphasis on training to innovate, and, in turn, generate greater financial performance. We test these hypotheses using a sample of 184 initial public offering (IPO) software firms that conducted their IPO between 1993 and 1996 and our results are consistent with our theorizing. Firms that utilized these human resource practices innovated more frequently and firms with more innovations had higher stock prices over time. Our findings combine to suggest a theoretical model of structural antecedents of a different type of reliability-intensity of innovation. Copyright (C) 2003 John Wiley \& Sons, Ltd.
\end{abstract}

\section{Introduction}

High-reliability organizations (HROs, e.g., nuclear power plants, nuclear aircraft carriers, and air traffic control) have often been characterized as too special, too exotic, and too 'far out' for the prosaic world of everyday organizations (Scott, 1994) and mainstream organization theory (LaPorte \& Consolini, 1991). Simultaneously and paradoxically, they have also been hailed as a source of valuable lessons for how all organizations can minimize error and handle peak demands (LaPorte, 1996) and as 'harbingers of adaptive organizational forms for an increasingly complex environment' (Weick, Sutcliffe, \& Obstfeld, 1999, p. 82). In this study we attempt to answer two questions that emerge from this paradox: Under what conditions do 'prosaic' organizations resemble 'exotic' HROs? Given a general resemblance, how do firms organize to replicate the exceptional performance of HROs?

* Correspondence to: Timothy J. Vogus, The University of Michigan Business School, 701 Tappan Street, Ann Arbor, MI 48109, U.S.A. E-Mail: tvogus@bus.umich.edu 
HROs are defined by their unique ability to operate high-hazard technological systems in a nearly error-free manner (Roberts, 1990). These organizations are constantly at risk of failure because their technologies are so complex that elements can combine in unforeseen ways and when errors occur they amplify rapidly because of tight coupling (Perrow, 1999). While ordinary organizations rarely operate such hazardous technologies, in many industries (e.g., software) or in an early stage of an organizational life cycle (e.g., IPO), some organizations find themselves in complex, rapidly changing, and tightly coupled organization-environment relations. When they face such environments these organizations become 'reliability seeking.' However, it is important to note that the reliability these organizations seek differs somewhat from that of HROs. While reliability entails an 'unusual capacity to produce collective outcomes of a certain minimum quality repeatedly' (Hannan \& Freeman, 1984, p. 153) in both settings, in tightly coupled and interactively complex organization-environment relations, reliability manifests itself as the capability to stay ahead of competitors and technological obsolescence through greater intensity of innovation (Brown \& Eisenhardt, 1997; D'Aveni, 1994).

Scholars have argued that reliability-seeking organizations address the tight coupling and interactive complexity of their organization-environment relations through mindfulness (Weick \& Sutcliffe, 2001; Weick et al., 1999). Mindfulness is appropriate for reliability-seeking organizations because it 'both increases the comprehension of complexity and loosens tight coupling' (Weick et al., 1999, p. 105) and encourages organizations to constantly probe their environments for ways to stay ahead through innovation (Brown \& Eisenhardt, 1997). We argue that mindfulness occurs as a byproduct of a set of human resource (HR) practices that help an organization remain vigilant and flexible. Specifically, HR practices that help infuse divergent perspectives (the use of skilled temporary employees), enable and increase bidirectional communication (positive employee relations), and recognize the need for updating skills and building new capabilities (an emphasis on training) should assist reliability-seeking organizations in their efforts to innovate.

In this study we examine a cohort of reliability-seeking firms, specifically software firms that conducted their initial public offerings (IPOs) between 1993 and 1996. The crux of our argument is that IPO software firms face environments that are interactively complex and to which they are tightly coupled, and, as a consequence, are reliability seeking. After establishing IPO software firms as reliability seeking we offer a conceptual framework for how these firms achieve innovation. To do so, we revisit and elaborate the concept of mindfulness, articulate the cognitive processes that underlie it, and theoretically connect mindfulness with human resource practices. Next we derive hypotheses articulating the relationship between use of skilled temporary employees, positive employee relations, and an emphasis on training and innovation. Finally we test our hypotheses using a sample of 184 IPO software firms and offer implications for HROs, mindfulness, and strategic human resource management.

\section{IPO Software Firms as Reliability-Seeking Organizations}

HROs need to maintain failure-free operations because their technologies are sufficiently hazardous that the first error can be the last trial. Two characteristics of these technologies make untoward outcomes both likely and disastrous: tight coupling and interactive complexity (Perrow, 1999). A system is tightly coupled when the component parts are interrelated in such a manner that there are few possible substitutions, time-dependent processes, and minimal slack and buffers (Perrow, 1999). A system is interactively complex when it is extremely difficult to anticipate all the ways in which the different components of a system will interact. Interactive complexity also increases the likelihood that when interactions do occur they will be unfamiliar or unexpected sequences that are not immediately comprehensible (Perrow, 1999, p. 78). 
While few organizations operate technologies as hazardous as those of HROs, we argue that a wider variety of organizations face conditions of tight coupling and interactive complexity in their organization-environment relations. To the extent that an organization is tightly coupled to an interactively complex environment, it becomes reliability seeking to avert the extreme risk and consequences of error inherent in such environments. These organizations seek greater intensity of innovation to cope with their demanding environments because 'failure to keep up is not met with leniency,' but rather with involuntary exit (D'Aveni, 1994, p. 217).

There are three sources of tight coupling in organization-environment relations that mirror the features identified by Perrow: resource dependence (limited substitutions), time pressure (time-dependent processes), and the liability of newness (Stinchcombe, 1965; minimal slack). The resource dependence perspective (Aldrich \& Pfeffer, 1976) asserts that organizations are incapable of generating all the resources necessary to maintain themselves and therefore must enter into exchanges with other organizations (i.e., the environment). To the extent that a firm is heavily reliant upon a single customer, partner, or supplier it creates tight coupling and minimizes possible substitutions for the provision of key resources in the event of a customer, partner, or supplier failing. The literature on high-velocity environments (e.g., Eisenhardt, 1989; Bourgeois \& Eisenhardt, 1988) illustrates how time-dependent processes occur in organization-environment relations. Time-dependent processes in these settings are rapidly opening and closing niches and 'strategic windows' which once missed often result in involuntary exit (Bourgeois \& Eisenhardt, 1988). Lastly, the liability of newness asserts that young organizations are at the greatest risk of failure because they have extremely limited resources and slack that make them vulnerable to even slight errors or disruptions (Stinchcombe, 1965).

IPO software firms face each of these conditions of tight coupling. First, these firms are often heavily reliant upon one customer, supplier, or strategic partner, which limits substitutions and creates resource dependence. Second, the environments facing IPO software firms closely mirror the time dependence of high-velocity environments described by Bourgeois and Eisenhardt (1988). IPO software firms face the constant threat of intense competition and technological obsolescence that necessitates swift and greater intensity of innovation. Lastly, IPO software firms face the liability of newness and the limited slack that accompanies it, as the vast majority of these firms tend to be young, small, and cash poor.

The presence of interactive complexity, unexpected and unfamiliar sequences, and incomprehensible interactions in organization-environment relations is well documented in prior research on hypercompetition (D'Aveni, 1994) and high-velocity environments (Eisenhardt, 1989; Bourgeois \& Eisenhardt, 1988). Hypercompetition erodes environmental stability and creates interactive complexity through shortening product life cycles, repeatedly introducing new technologies, frequent entry by unexpected outsiders, repositioning by incumbents, and radical redefinitions of market boundaries as diverse industries merge (D'Aveni, 1994). High-velocity environments are those in which there is 'rapid and discontinuous change in demand, competitors, technology and/or regulation, such that information is often inaccurate, unavailable, or obsolete' (Bourgeois \& Eisenhardt, 1988, p. 816). These conditions are important to our current discussion because they make it especially difficult to predict the significance of a change as it is occurring. That is, high-velocity conditions create the unfamiliar and the incomprehensible.

The environment facing IPO software firms is interactively complex, hypercompetitive, and high velocity. The complexity results from rapid and discontinuous technological change and the erosion of traditional market boundaries and categories. For example, consider some of the significant technological advances that have occurred during the period under study (1993-1999): multimedia, Internet, LAN-based networks, and the JAVA programming language to name just a few (Bogner \& Barr, 2000; Brown \& Eisenhardt, 1997). At the same time market boundaries were being blurred as software began its convergence with telecommunications and consumer electronics. In sum, both hypercompetition and high-velocity environments increase the potential for the unexpected and the 
unfamiliar because change is rapid, endemic, and discontinuous, and boundaries are permeable and ever shifting. Under such circumstances, it is impossible to anticipate future technological or competitive landscapes.

While their environments may be impossible to anticipate due to interactive complexity, reliabilityseeking organizations cannot simply utilize a 'wait and see' strategy because it may also result in failure, as competitive positions change and windows of opportunity close. Therefore, reliability-seeking organizations attempt to navigate their treacherous environments through tactics that help them to constantly probe their environments for ways to stay ahead through innovation. One strategy for coping with tightly coupled and interactively complex organization-environment relations is through pursuing a strategy of continuous change that not only reacts to the environment, but also enacts and creates it through innovation (Brown \& Eisenhardt, 1997). D'Aveni (1994) similarly advocates a proactive strategy of hypercompetitive behavior whereby firms utilize innovation to actively shape their environments and continuously generate new competitive advantages and destroy, obsolete, or neutralize the opponent's competitive advantage. In the next section, we build on this analysis and hypothesize how three HR practices (use of skilled temporary employees, positive employee relations, and an emphasis on training) work through three underlying mechanisms (reluctance to simplify interpretations, sensitivity to operations, and commitment to resilience) to help reliability-seeking organizations stay ahead through innovation.

\section{Theory and Hypotheses}

\section{Mindfulness ${ }^{1}$}

The theoretical mechanisms underlying the proposed relationship between HR practices and innovation are mindfulness and its constituent processes. Mindfulness entails an 'enriched awareness ... [through] active differentiation and refinement of existing categories and distinctions ... creation of new discontinuous categories out of the continuous stream of events ... and a more nuanced appreciation of context and alternative ways to deal with it' (Weick et al., 1999, p. 90). We choose mindfulness for three reasons. First, mindfulness has been proposed as a concept to bridge HROs and other reliability-seeking organizations because reliability in both settings is theorized to emerge from 'the input side: what they pay attention to, how they process it, and how they struggle to maintain continuing alertness' (Weick \& Sutcliffe, 2001, p. 19). Second, mindfulness is of critical importance to reliability-seeking organizations as it allows them to more readily detect weak signals from interactively complex environments earlier and respond to them more effectively. Mindfulness also loosens tight coupling by creating alternative paths of action. Lastly, mindfulness should also enhance a firm's ability to innovate because 'creating new categories, exploring multiple perspectives, and focusing on process all increase the possibility that a novel approach to a problem will be discovered' (Langer, 1989, p. 139).

In their elaboration of the processes of collective mindfulness Weick and colleagues (Weick \& Sutcliffe, 2001; Weick et al., 1999) identify five processes that contribute to creating and sustaining the enriched awareness of mindfulness: reluctance to simplify interpretations, sensitivity to operations, commitment to resilience, underspecification of structures, and preoccupation with failure. Reluctance to simplify interpretations entails seeking out and maintaining divergent viewpoints and skepticism to

\footnotetext{
${ }^{1}$ When we refer to mindfulness, we are referring to it at the system or organization level (i.e., collective mindfulness, Weick et al., 1999). To the extent we invoke Langer's work $(1989,1997)$, which was derived from work on individuals, we focus on her references to the group or organizational level of analysis.
} 
minimize blind spots and ensure key variables are not overlooked. Sensitivity to operations means creating and maintaining an integrated big picture of the moment through ongoing attention to real-time information (Weick et al., 1999). Commitment to resilience is the belief in the fallibility of existing knowledge as well as the ability to both bounce back from errors and handle surprises in the moment (Wildavsky, 1988). The underspecification of structures results from the fluid decision-making that occurs in HROs during high-tempo times. During these periods, decisions migrate to the individuals in the organization with the greatest expertise and closest to the problem (Roberts, Stout, \& Halpern, 1994). Lastly, organizations preoccupied with failure treat any failure or near miss as an indicator of the reliability and health of the system and reward the reporting of errors (Weick et al., 1999).

In this study we theorize that three of these processes - reluctance to simplify interpretations, sensitivity to operations, and commitment to resilience — are the theoretical mechanisms underlying the relationship between HR practices and innovation. We focus on these three processes because they are crucial to sensing and anticipating change and reacting swiftly. That is, they are the essential infrastructure for staying ahead. Although the other two processes are important to the performance of HROs, we exclude them because they are probably invariant in this sample as small and young firms are preoccupied with failure (Stinchcombe, 1965) and underspecify their structures (Aldrich, 1999) out of necessity.

While all organizations are likely to derive some benefit from mindful operations, the value of mindfulness increases to the extent that an organization faces a tightly coupled and interactively complex environment. Thus, the benefits of mindfulness and its constituent processes are largely contingent upon a firm being an HRO or reliability seeking. The benefits of mindfulness are contingent because although most of the extant literature on mindfulness treats it as an unmitigated positive (e.g., Weick \& Sutcliffe, 2001; Langer, 1989, 1997), there are significant costs associated with creating and maintaining mindfulness (LaPorte, 1996). In addition, maintaining mindfulness in a stable environment could cause efficiency losses as a firm unnecessarily expends resources on updating its picture of its environment (e.g., through scanning) when nothing or very little has changed.

\section{HR practices and mindfulness}

The cornerstone of our argument is that HR practices are the source of innovation and act as the structural starting point for mindful processing. HR practices have been shown to play a significant role in preserving the nearly error-free performance of HROs (Gaba, 2000; Rochlin, LaPorte, \& Roberts, 1998; Weick \& Roberts, 1993). Existing research in the strategic human resource management literature provides additional support for this line of thinking. For example, Ichniowski, Shaw, and Prennushi (1997) found that several HR practices including employee involvement in problem-solving teams, job rotation, regular sharing of information, and training increase production-line reliability in steel minimills. Although Ichniowski et al. (1997) did not label their findings in the same way, each of their practices can be readily recast as enhancing reliability through the processes of collective mindfulness: reluctance to simplify interpretations, sensitivity to operations, and commitment to resilience. First, employee involvement in multiple problem-solving teams and job rotation both create the capacity to remain reluctant to simplify interpretations as multiple and divergent perspectives are brought to bear on problemsolving and routine operations. Second, regular sharing of information between employees and management endows both with a sense of an integrated big picture of plant operations and in doing so constructs a sensitivity to operations. Lastly, investment in off-line training increases each employee's coping skills and ability to resiliently improvise a response in the face of the unexpected.

Extending this logic and prior work on HROs, we test the impact of a firm's HR practices on intensity of innovation. We argue that HR practices facilitate innovation by enabling and relying upon three of the processes of collective mindfulness: reluctance to simplify interpretations, sensitivity to 
operations, and commitment to resilience. These postulated, but unmeasured, theoretical mechanisms underlie each of the hypothesized HR practice-innovation relationships as follows: the use of skilled temporary employees creates divergent ideas and a reluctance to simplify interpretations, positive employee relations create a climate that facilitates intensive ongoing communication and a sensitivity to operations, and an emphasis on training values recovery skills and resilience and builds the competence to enable them. While these processes of mindfulness are theorized as byproducts of the HR practices, we only hypothesize and test the direct relationship between HR practices and innovation.

\section{Use of skilled temporary employees}

In order to cope with the complexity of their environments, HROs and reliability-seeking organizations are motivated to remain reluctant to simplify their interpretations, which means they make fewer assumptions and take deliberate steps to create a complete and more nuanced picture (Weick \& Sutcliffe, 2001). At its core a reluctance to simplify interpretations is maintaining divergent perspectives and broad repertoires of action. Using skilled temporary employees triggers a reluctance to simplify interpretations because these employees introduce different ways of seeing that allow an organization to notice more in its environment and create a greater number of potential recombinations of existing knowledge. Prior research suggests that the use of skilled temporary employees unleashes three mechanisms that increase divergence and innovation potential: conceptual slack (Schulman, 1993), minority influence (Nemeth, 1997; Nemeth \& Staw, 1989; Nemeth, 1986; Nemeth \& Kwan, 1985), and slow learning (March, 1991).

One of the primary contributions of skilled temporary employees to an organization is conceptual slack (Schulman, 1993). Schulman (1993) defines conceptual slack as 'a divergence in analytical perspectives among members of an organization over theories, models, or causal assumptions pertaining to its technology or production processes' (p. 364). Conceptual slack forces an organization to take less for granted and to remain vigilant. This added vigilance is likely to produce new ideas and modes of operating that can become innovations.

Skilled temporary employees also stimulate divergence through processes of minority influence (Nemeth, 1986). Minority views, even when they are wrong, stimulate the majority to exert more cognitive effort and think in more divergent ways. Laboratory work conducted by Nemeth and Kwan (1985) found that exposure to persistent minority views led to increases in divergent and original thought. Thus, skilled temporary employees, through minority influence, are likely to enhance innovativeness. Langer (1989) also supports the view that skilled temporary employees encourage divergent and original thought as she notes, 'the imaginative use of "outsiders" [e.g., independent consultants] can encourage ... mindfulness ... [and] can keep important questions flowing' (p. 139).

Skilled temporary employees are also likely to increase innovation because they offer expertise that benefits the organization, but are 'slow learners' in that they are slowly socialized and thus maintain their divergent perspectives and stimulate further 'exploration' and innovation (March, 1991). In further support of the idea that temporary employees will retain divergent perspectives over time, Levesque, Wilson, and Wholey (2001) found that temporary software development project teams fail to converge on a shared mental model.

Theorizing the use of temporary employees as a reliability-enhancing strategy may seem counterintuitive to scholars of HROs. For example, Rousseau and Libuser (1997) and Kochan, Wells, and Smith (1992) have documented how inexperienced and untrained temporary workers have played a significant role in organizational accidents in the construction, mining, and petrochemical industries as well as the crash of a ValuJet DC-9. We argue that temporary employees enhance innovation as a result of the unique nature of temporary employees in high-technology industries. Unlike the 
temporary workers in construction, mining, and petrochemicals, temporary employees and contractors in high-technology industries (e.g., software) are found to rival permanent employees in performance and skills (Jarmon, Paulson, \& Rebne, 1998).

In sum, the use of skilled temporary employees should facilitate innovation because innovation requires preserving (not reducing) the uncertainty and diversity in the environment within the organization' (Van de Ven, 1986, p. 605). To the extent that using skilled temporary employees preserves uncertainty and multiple perspectives we hypothesize.

Hypothesis 1: Firms that utilize skilled temporary employees will achieve greater intensity of innovation.

\section{Positive employee relations}

To maintain high performance under challenging conditions, HROs engage in extensive information sharing across organizational levels that helps create an integrated big picture of operations in the moment. Weick et al. (1999) refer to this comprehensive view of current operations as sensitivity to operations. The frequent review of performance, operations, and environmental conditions embedded in sensitivity to operations allows detection of problems and opportunities sooner, develops intuition and flexible options, deepens personal knowledge of the enterprise, and facilitates improvisation to cope with the unclear and changing environment (Brown \& Eisenhardt, 1997; Eisenhardt \& Tabrizi, 1995). This frequent review and updating is essential in reliability-seeking organizations because the pace, frequency, and scale of change they face quickly render information inaccurate, obsolete, or unavailable. In IPO software firms the operations being attended to are the product development process. However, we take a broader 'communication web' view of product development that asserts the better that members are connected with one another and key outsiders (e.g., top management, sales and marketing, and customers), the more successful and innovative the development process (Brown \& Eisenhardt, 1995).

Positive employee relations contribute a supportive organizational climate where people can build a big picture through extensive communication and information sharing. The impact of positive employee relations on communication and information sharing has been extensively discussed in the strategic human resource management literature under several labels, including commitment-maximizing systems (Arthur, 1992), mutual investment (Tsui, Pearce, Porter, \& Tripoli, 1997), and highperformance work systems (Pfeffer, 1994, 1998). Each of these systems helps produce innovation by way of increasing real-time communication and updating across levels. First, Arthur (1992) describes employee relations in a commitment-maximizing system as enabling high levels of employee participation and involvement in decision-making as well as regular sharing of information with employees. Second, Tsui et al. (1997) describe a mutual investment employment system as an employer's extended consideration of an employee's well-being and career within the firm in exchange for the employee's willingness to be flexible, assist junior colleagues, and consider the unit's or organization's interests as important as core job duties. Mutual investment is associated with citizenship behaviors that include offering suggestions, expressing opinions, and frequently talking to management about process improvement (p. 1104). Third, Pfeffer $(1994,1998)$ finds similar information sharing and empowerment as essential components of high-performance work systems and effective performance.

Conversely, negative employee relations create conditions that undermine sensitivity to operations. For example, downsizing increases worries, work pressures, overload, and, consequently, reduces employee interaction and communication of critical information that leads to errors of omission and insufficient understanding of organizational systems (Perron \& Friedlander, 1996). 
Other literature also suggests how the real-time information gathering engendered by positive employee relations promotes innovation. Eisenhardt and colleagues' work on fast product development and innovation suggests that firms perform better and innovate more frequently to the extent that they act according to a constantly constructed, refined, and integrated picture of internal operations and their environment through extensive exchange of real-time information (Brown \& Eisenhardt, 1997; Eisenhardt \& Tabrizi, 1995). Waller (1999) similarly finds that in the complex and demanding environment of flight operations frequent and early updating of an unfolding situation through information collection and transfer leads to greater performance and successful adaptation to novel events.

In sum, positive employee relations and the communication it engenders enhance a firm's capabilities for remaining sensitive to ongoing operations. This sensitivity reduces the incidence and impact of surprises because maintaining sensitivity to operations entails constantly refining categories based on real-time information, giving rise to innovation. Thus, we hypothesize.

Hypothesis 2: Firms with positive employee relations will achieve greater intensity of innovation.

\section{Emphasis on training}

In HROs, their ability to cope with the constant threat of surprise relies on their commitment to resilience. Resilience entails both the ability to 'absorb change and still persist... [and] to utilize the change that is absorbed' (Weick et al., 1999). HROs behave resiliently by preparing for inevitable surprise and 'expanding general knowledge and technical facility, and generalized command over resources' (Wildavsky, 1988, p. 221) through extensive training. An emphasis on training entails recognizing that current skills are likely inadequate for possible future environments and that regular acquisition, updating, and refreshing of skills are essential. By focusing on the frailty of current knowledge and the inevitability of the unexpected, an emphasis on training embodies a commitment to resilience. This finding has been corroborated in studies of aircraft carriers (Rochlin et al., 1998; Weick \& Roberts, 1993; Roberts, 1990), banking (Roberts \& Libuser, 1993), and health care (Gaba, 2000). Just as importantly, lack of training is often cited as a reason why small perturbations in a system amplify to disasters. In summarizing the explosion at Bhopal, Roberts (1990) notes 'the potpourri of human factors contributing to the accident might be summarized as factors brought by poor training and motivation, by inadequate staffing, and the lack of core values emphasizing safety reliability' (p. 164, emphasis added).

The capacity to both absorb and harness change is also crucial to reliability-seeking organizations as their ability to quickly sense and respond to their extremely dynamic environments determines their ability to remain viable. Hambrick and Crozier (1985) find that successful rapid-growth firms, like HROs, recognize their frailty and place an emphasis on training and providing people with skills before they are crucial. Training should facilitate remaining viable through innovation because '[i]f people think they can do lots of things, then they can afford to pay attention to a wider variety of inputs because, whatever they see, they will have some way to cope with it' (Weick, 1988, p. 311) and, by extension, they will be better equipped to improvise novel solutions. Wright and Snell (1998) describe a similar process of 'flexibility,' at the organizational level of analysis, 'as the extent to which the firm's human resources possess skills and behavioral repertoires that can give a firm options for pursuing strategic alternatives' (p. 761). Firms with more strategic options can foresee and navigate more potential environments and more readily recombine these options into novel actions. To the extent that an emphasis on training fosters a commitment to resilience by building broad behavioral repertoires and the capability for improvisation leads us to hypothesize. 
Hypothesis 3: Firms emphasizing training will achieve greater intensity of innovation.

Prior research on HROs has noted that HROs pursue reliability at the expense of efficiency (Schulman, 2002; Creed, Stout, \& Roberts, 1993). HROs trade off efficiency for reliability because short-term efficiency may significantly undermine long-term viability by causing an organization to make potentially fatal errors of omission. While reliability-seeking organizations are less able to make these trade-offs, to the extent that their environments demand considerable innovation, they will likely favor exploration at the cost of exploitation (March, 1991). Thus although each of the HR practices should positively affect intensity of innovation, it may come at the cost of short-term macro performance indicators such as stock price. The trade-off occurs because firms have to explore and maintain more ideas, refresh their picture of the environment more frequently, and regularly build capacity to meet the demands of ever-changing environments in order to innovate. As a result, these firms are often unable to reap the efficiency gains of routinization and standard operating procedures. On the other hand, greater intensity of innovation should positively impact financial performance for two reasons. First, prior research on innovation (i.e., patenting), suggests that the volume of innovation acts as a leading indicator of financial performance and is 'reliably associated with the future performance... in capital markets' (Deng, Lev, \& Narin, 1999, p. 20). Second, 'in a world of uncertainty, potential members, investors, and clients may value reliability' (Hannan \& Freeman, 1989, p. 72). Having a greater number of innovations (i.e., patents) sends a clear signal about a firm's level of technical knowledge and its ability to stay ahead of technological progress through innovating. In addition, for some IPO software firms a patent is their most marketable asset (Wilbon, 1999). To the extent that the HR practices of reliability-seeking organizations favor exploration and innovation over exploitation and efficiency, and innovations are important signals of reliability and future performance, we hypothesize.

Hypothesis 4: Intensity of innovation will mediate the relationship between skilled temporary employees, positive employee relations, and an emphasis on training and financial performance.

In sum, we hypothesize that the use of skilled temporary employees, positive employee relations, and an emphasis on training all result in greater intensity of innovation. These innovations, in turn, result in greater financial performance. Figure 1 summarizes the hypotheses graphically. Figure 1 also illustrates that we theorized, but did not measure, that HR practices lead to greater intensity of innovation through reluctance to simplify interpretations, sensitivity to operations, and commitment to resilience. In the next section we will discuss the sample, data collection and coding, variable definitions, operationalizations, and the statistical methods utilized.

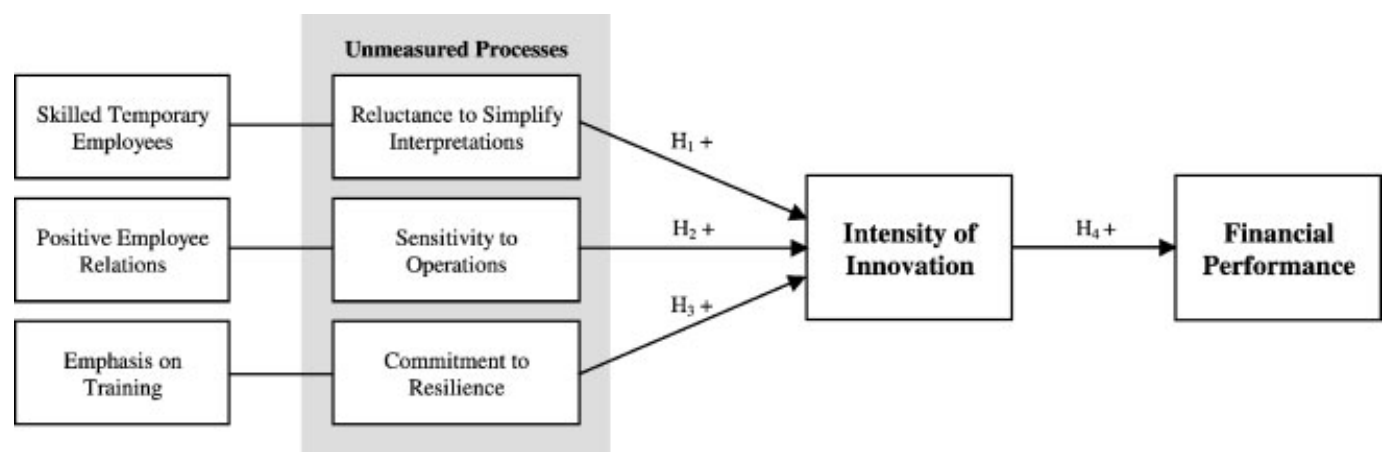

Figure 1. A conceptual model of HR practices, mindful processes, intensity of innovation, and financial performance 


\section{Organizational Context}

\section{IPO Software Firms and their Environments}

The IPO software firms in this study exist in an extremely precarious position due to the characteristics of these firms and the nature of the competitive environments. Generally, these firms are small (i.e., fewer than 100 employees), young (less than 7 years old), and cash poor (even after the infusion of cash through the IPO process). Each of these characteristics makes these firms especially vulnerable even to slight disruptions because they have extremely limited resources and slack. These traits are exacerbated by the nature of the relations these firms have with other organizations in their environments. For example, IPO software firms are often heavily reliant on one customer, supplier, or strategic partner. If any one of these other organizations were to fail, it is likely the IPO software firm would also fail because they have no other options. IPO software firms are also embedded in intense competitive environments where missing a 'window' for developing and introducing a product or failing to swiftly and continuously innovate is also met with failure.

\section{Technological Change in the 1990s}

During the period under study, 1993-2000, IPO software firms faced rapid, endemic, and discontinuous technological change. For example, several significant technological advances occurred during this period, including: multimedia, Internet, LAN-based networks, and the JAVA programming language. At the same time the nature of technological changes was becoming more fundamental and transformational as software began its convergence with telecommunications and consumer electronics such that changes in one area had rapid and significant ramifications for the others.

\section{The Rise of the Software Patent}

Given the discontinuous change facing IPO software firms (and the software industry more generally), firms began to utilize patenting as a strategy for capturing more of the financial benefits from their innovations. Prior to the 1990s, the less costly and time-consuming process of copyrighting software had been the primary mode of intellectual property protection, but copyright protection was significantly eroded in the 1995 Lotus v. Borland decision that ruled that 'second movers' must be allowed to emulate and extend the innovator's code and methods. As such, software-related patents have grown tremendously over the past decade from virtually zero in the 1970s and 1980s to 3600 in 1993 and 8100 in 1996 and 17,500 in 1998. The major advantage of patents for software firms is that they preclude others from making commercial use of a patented technique, even if it is developed with no knowledge of the patented work, as long as the patent is in force. Most noteworthy was the 1994 decision of Stac Electronics v. Microsoft, where the court awarded Stac $\$ 125$ million as a result of Microsoft violating their patent. While the fine did not significantly damage Microsoft, it did help Stac remain viable as Microsoft's infringing product had to be withdrawn from the market. This case gave further impetus for small firms like those in our sample to pursue patents in order to stave off larger competitors. While patenting became increasingly popular during the 1990s and offered considerable benefits for the patenting firms, it did not do so without considerable controversy. The practice of patenting software led to the emergence of groups of extremely vocal detractors (e.g., the League for Programming Freedom) who asserted that software patents undermined the collaboration that fuels the U.S. software industry and are often improperly granted to widely known practices or algorithms that fail to meet the patent and trademark office's 
litmus test of being 'novel and nonobvious.' More specifically, these detractors point to the granting of 'overly broad' patents such as in 1993 when Compton's New Media was granted a patent on the process and concept of multimedia (Shulman, 2000). Although Compton's patent was subsequently revoked and the patent and trademark office has significantly increased staffing and improved its database of prior art (i.e., previously granted patents) that helps narrow the claims of new patents, software patents remain controversial.

\section{Methods}

\section{Sample}

The initial sample was drawn from all software firms that conducted their IPO between 1993 and 1996 ( $N=269$ firms). We define software firms as firms in SIC codes 7371 (computer programming services) and 7372 (prepackaged software). We chose these two segments because they are a locus of innovation in the software industry as well as extremely competitive segments. Furthermore, the distinction between the prepackaged software and computer programming services segments has blurred during recent years as many of these firms have merged and begun competing in each other's sectors (Steinmueller, 1996). SIC code 7373 (computer-integrated system design) also comprises a significant portion of computer software industry revenue and innovation, but we exclude it from our analysis because firms in this segment also derive a portion of their revenue from computer hardware. Competing in the hardware market is problematic because these firms face different competitive conditions and patenting conventions. Although these industry categorizations are fairly coarse grained, in that the firms in a four-digit SIC code may never directly compete, a more fine-grained distinction would require a much larger sample. For example, the Software Encyclopedia (1999) categorizes the software industry into 39 segments and hundreds of subcategories. More importantly, in the hypercompetitive and interactively complex environments that reliability-seeking organizations face, any firm in a related industry is a potential and plausible competitor. Thus, further segmenting the sample may overly compartmentalize what are truly fluid and permeable boundaries. We also eschew a more fine-grained analysis of sectors because all the firms do compete in one critical arena-the labor market for technical talent. They all seek to attract and retain the top programmers and technical staff (and they so note repeatedly in their prospectuses).

Moreover, in order to adequately test our hypotheses regarding the intensity of innovation we needed to examine the dependent variables over a relevant period of time (i.e., 3 years after the IPO), and this reduced our sample size. Of the 269 software firms that conducted their IPO between 1993 and 1996, 85 (32 per cent of the original sample) had either gone bankrupt, merged, been acquired, or had been delisted by the SEC. This reduced our final sample to 184 . We accept a reduced sample because it is essential to our theoretical argument to observe the firms' ability to innovate over time. The 184 firms in the final sample were on average 7 years old $(\mathrm{SD}=4.79)$. The median firm, however, was 6 years old, and the range was from 1 to 27 years old. Given the age data were skewed, we logarithmically transformed the variable. The average firm in the sample employed 238 people ( $\mathrm{SD}=706.60$ ). The median firm had 132 employees with a range from 11 to 9200 . Given the skewed size distribution, we again used the logarithm of the number of employees in the analyses. Each U.S. geographic area is represented in the sample and 31 per cent of the firms are headquartered in Silicon Valley. International firms comprised 3.8 per cent of the sample. Table 1 reports the means, standard deviations, and medians for the variables used in the analyses. 


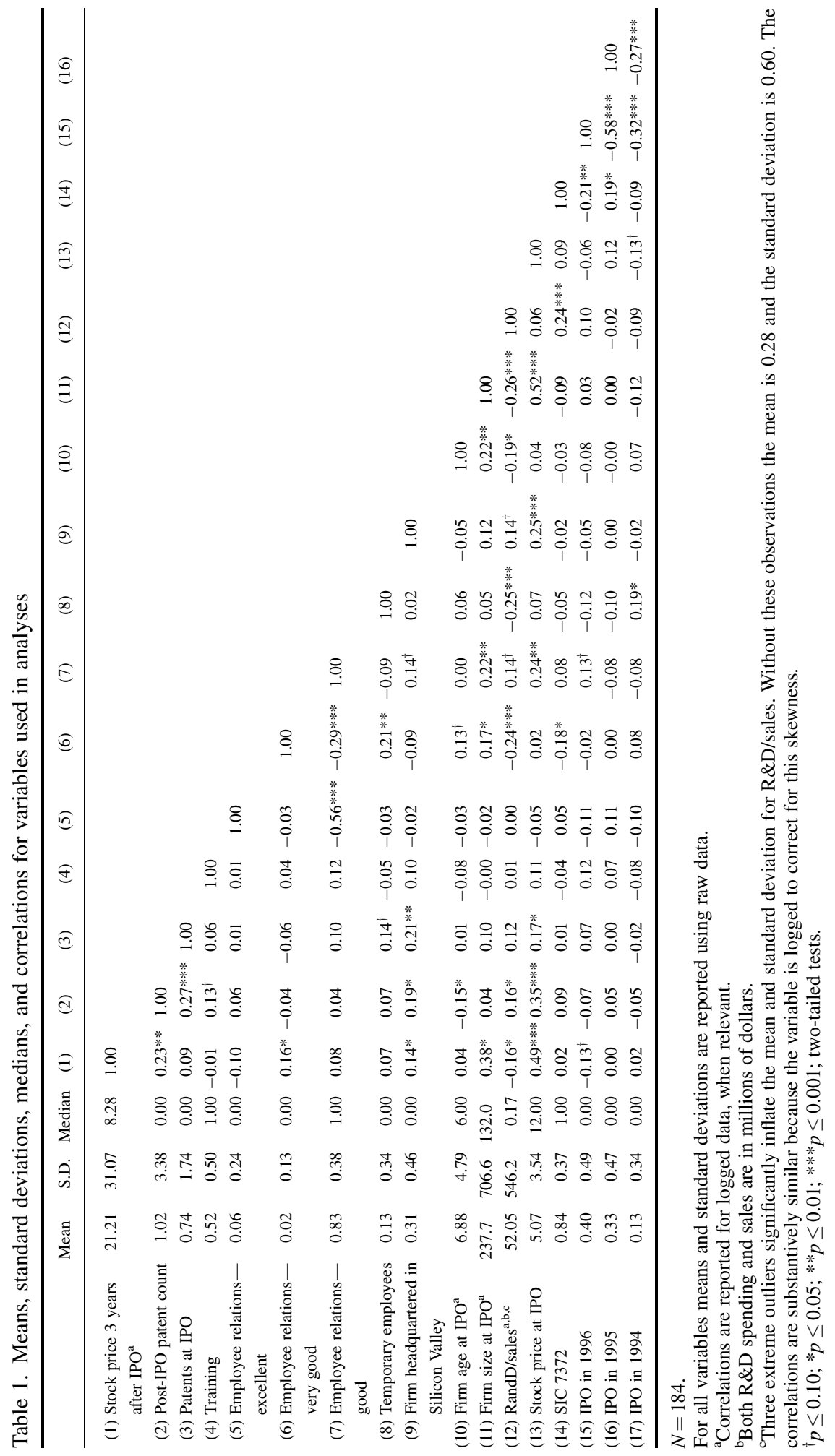




\section{Data collection and coding}

The primary data source was the prospectus of each firm in the sample. The prospectus is the document filed with the Securities and Exchange Commission (SEC) prior to a firm's IPO. Strict guidelines govern the content and the format of a prospectus and firms are legally liable for any information that might mislead investors (O'Flaherty, 1984). The Securities Act of 1933 sets specific requirements for the prospectus and thereby insures its consistency. The typical prospectus-writing process involves two investment banking firms, multiple lawyers, and a certified public accountant (Welbourne \& Cyr, 1999). Each party has a vested interest and a legal obligation to provide an honest and accurate assessment of a company. The utility and validity of the prospectus as a data source have also been demonstrated in prior research (e.g., Welbourne \& Cyr, 1999; Welbourne \& Andrews, 1996). The coding strategy employed for this study is similar to that used by Welbourne and Andrews (1996) and Welbourne and Cyr (1999). Code sheets and a coding handbook were given to each of five coders after an initial training session. This team of coders also met with one of the authors on a weekly basis to discuss problems and inconsistencies in the coding process. We also randomly cross-coded every tenth prospectus. For the variables used in this study, inter-coder agreement was 90 per cent or higher. This inter-coder agreement reflects the percentage of exact matches between a coder and a cross-coder. We also conducted additional tests to ensure there was adequate correspondence between coders. All intercoder correlations were greater than 0.885 and the Spearman-Brown formula of effective reliability (Lee, Hallahan, \& Herzog, 1996) produced values greater than $0.938 .^{2}$ In addition to the prospectus, additional financial and patent data was obtained from the following sources: COMPUSTAT for financial data, CRSP and Going Public: The IPO Reporter for stock price data, and the U.S. Patent and Trademark Office database for patent data.

\section{Variables}

\section{Dependent variables}

Intensity of innovation. We use patents as our measure of innovation and a dependent variable. We operationalize a firm's intensity of innovation as the number of post-IPO patents. Patents are included in the dependent variable as long as the firm applied for the patent after the date of their IPO, prior to 3 years after their IPO, and the patent was granted by December 31, 2000. This operationalization of intensity of innovation corresponds to our theoretical definition of reliability as 'an unusual capacity to produce collective outcomes of a certain minimum quality repeatedly' (Hannan $\&$ Freeman, 1984, p. 153). First, a patent is a collective outcome because it is often the result of collective research (i.e., the patent is granted to multiple researchers) and even if it isn't the process of patenting enlists multiple personnel throughout the organization (e.g., technical, managerial, and legal staff). Further, a patent is ensured to be of a certain minimal quality based on the elaborate, and often lengthy, process for approving a patent by a patent examiner at the U.S. Patent and Trademark Office, which ensures each patent granted meets the threshold of being a 'novel and nonobvious' invention and that the claims of the patent are not overly broad and do not impinge upon previously granted patents (i.e., 'prior art'). Second, to the extent that a firm has greater intensity of innovation (i.e., more patents) during a given period, they have produced 'collective outcomes of a certain minimum quality repeatedly' or multiple times. Three years is a relevant window over which to assess a firm's intensity

\footnotetext{
${ }^{2}$ The Spearman-Brown coefficient is calculated using the following formula $n r / 1+(n-1) r$, where $n=$ number of coders and $r=$ average intercorrelation of the coders ratings. The Spearman-Brown formula is interpreted like other measures of effective reliability such as Cronbach's alpha.
} 
of innovation because it allows each firm to process at least one cohort of patents (the software patent process usually take between 18 and 30 months, although the lag time has decreased in recent years).

The use of patents as a proxy for innovation has a long history in economics (see Griliches, 1990, for a review) and has been used in a variety of industries, including pharmaceuticals (Cockburn \& Henderson, 1998), semiconductors (Sorensen \& Stuart, 2000), biotechnology (Powell et al., 1996), and chemical processing (Ahuja, 2000). While the plethora of studies using patents as a measure of innovation help justify our usage, patenting in the software industry has a unique history that merits further explanation. This history is the type of contextual factor that Rousseau and Fried (2001) assert is of critical importance to nuanced analysis in organizational behavior. Patenting in the computer software industry (and patenting software in general) has an extremely contentious history. Software patents have some extremely vocal detractors (e.g., the League for Programming Freedom) that assert patents undermine the collaboration that fuels the U.S. software industry and are often improperly granted to widely known practices or algorithms, which fail to meet the patent and trademark office's litmus test of being 'novel and nonobvious.' These unique circumstances lead us to utilize zero-inflated Poisson regression, which accounts for the fact that some firms may systematically not attempt to patent (e.g., they consider the patent approval process too costly or software patents ideologically problematic). This method accounts for the fact the not all firms are equally likely to patent and we describe this method in more detail in the results section. We also believe that three additional factors render patents a useful proxy for innovation.

First, capitalizing on and protecting innovation through patents is of utmost importance to these nascent firms. In the sample more than 84 per cent of the firms noted the risk of not gaining or losing a patent and more than 90 per cent cited the risk of technological obsolescence as material risks to their continuing viability in the risk factors section of their IPO prospectus. The major advantage for software firms is that patents preclude others from making commercial use of a patented technique, even if it is developed with no knowledge of the patented work, as long as the patent is in force (Nichols, 1998). Second, patents have also become increasingly popular in the industry. The number of software-related patents has grown tremendously over the past decade from virtually zero in the 1970s and 1980s to 3600 in 1993 and 8100 in 1996 (Nichols, 1998) and 17500 in 1998 (Erickson, 1999). Lastly, the firms in our sample with the highest patent counts (e.g., Netscape Communications) corresponded with qualitative rankings of 'most innovative' and 'best software applications' by industry analysts from trade magazines (e.g., Publish!, PC, PC Computing, and Windows as summarized in the Software Encyclopedia, 1999).

Financial performance. In order to test the impact of innovation on more macro, less proximate performance outcomes, we conducted analyses using stock price as a dependent variable. Stock price is arguably the most important indicator of financial health for IPO firms (Ibbotson \& Ritter, 1995). Stock price has also been suggested as an important outcome of effective HR practices (e.g., Welbourne \& Andrews, 1996; Abowd, Milkovich, \& Hannon, 1990). The variable is measured as stock price (adjusted for splits, buybacks, and changes in the underlying capital structure that may affect unit price) 3 years after IPO. The variable is then logarithmically transformed to correct for skewness in its distribution.

\section{Independent variables}

Skilled temporary employees. We code temporary employees using a dummy variable (1) if a firm mentions the current use of temporary employees, independent contractors, consultants, or contingent workers. Part-time workers are not included in the measure of temporary employees. While these distinctions may embody differences on a number of dimensions (e.g., career possibilities; see Kalleberg, 2000, for a comprehensive review of these different types of work and their 
consequences), they are all substantively similar in terms of their contribution to the organizationexpertise and divergent perspectives without incurring fixed costs. Although these workers are similarly utilized throughout our sample, the measure admittedly smoothes over what may be significant differences between temporary employees, independent contractors, contingent workers, and consultants, so the results should be taken as suggestive. However, statistical testing using this measure should be considered a strong test because the measure has a great deal of noise that could obscure statistical significance.

Positive employee relations. The SEC requires employers to rate their employee relations as either poor, satisfactory, good, very good, or excellent (Welbourne \& Andrews, 1996). We code employee relations as three dummy variables (excellent, very good, and good) because it is unclear that the differences between satisfactory and good, good and very good, very good and excellent are of the same magnitude, which is a necessary precondition for an ordinal measure. Satisfactory acts as the base category. Poor is not included as a category in the analysis because no firms in the sample rated their employee relations as poor.

Emphasis on training. An emphasis on training is a dummy variable coded 1 if the firm mentions employee training in the prospectus and 0 otherwise. We view the mention of training as significant because it illustrates the relative importance of training vis-à-vis other potential practices (Welbourne \& Andrews, 1996). Even this minimalist coding of training surfaces considerable variation as nearly half (48 per cent) of the firms in the sample make no mention of training.

\section{Mediating variable}

Intensity of innovation. The mediator proposed in Hypothesis 4 is the intensity of innovation. While this measure is largely consistent with our dependent variable, we adjusted the measure for use as a mediator to ensure that it was temporally prior to our measure of financial performance. We specifically measured the mediating variable as the number of patents filed after the date of IPO (e.g., 1993) and granted prior to the end of the third year after IPO (e.g., 1996). While this adjusted measure seems contemporaneous with the dependent variable (i.e., stock price 3 years after IPO), in practice no firms patented within 1 month of the end of the third year after IPO. Thus, a slight lag exists. A short or no lag, however, appears to be appropriate based on prior theoretical and empirical work. Theoretically, the efficient market hypothesis (Fama, 1970) posits that the stock price takes into account the value of all relevant available information. Once granted, patents become publicly available information and as such should be quickly incorporated into a firm's stock price. Furthermore, prior empirical work by Cockburn and Griliches (1988) finds that the stock market values 'news' in $R \& D$ (i.e., new patents).

\section{Control variables}

Based upon a review of the patenting/innovation (Sorensen \& Stuart, 2000; Griliches, 1990) and the strategic human resource management literatures (Welbourne \& Cyr, 1999; Welbourne \& Andrews, 1996; Huselid, 1995) we include the following control variables previously demonstrated to have effects on innovation, patenting, and firm performance.

Firm age. Consistent with Sorensen and Stuart's (2000) finding that older firms are more prolific at patenting, we control for age. Age is measured as the natural log of the year of incorporation subtracted from the year of IPO. We take the natural logarithm of this variable to correct for skewness in its distribution. Year of incorporation is used instead of year of founding because many firms did not report the year of their founding and because the nature of the business may have substantially changed between the year of founding and incorporation. 
Firm size. We measure size as the natural logarithm of the total number of employees at the time of IPO. We take the natural logarithm of the number of employees to control for the skewness in the size distribution. Because some software firms have no revenues and are considered 'development stage' companies with primarily intangible assets, headcount is an appropriate measure of size. Results are virtually identical using sales instead of number of employees as a measure of size (the two measures are highly correlated, $r=0.95, p<0.001$ ).

Prior patents. Given that firms may not pursue patenting because the process is too costly, too slow, or too contrary to their ideology, it is likely that firms that patent prior to their IPO will patent afterwards. We measured prior patents utilizing a count variable rather than a dichotomous variable because all patenting firms are not equal and a firm with five patents at IPO should be more likely to patent after its IPO than a firm with only one. In other words, firms that have applied for and received many patents have a lower cost of patenting or a lower threshold for filing for a patent (Sorensen \& Stuart, 2000). Prior patents are measured as the total number of patent applications filed and granted prior to the IPO date.

R\&D intensity. R\&D activity has a well-established relationship and long history in studies of patenting (e.g., Griliches, 1990; Hausman, Hall, \& Griliches, 1984). We calculate R\&D intensity by dividing R\&D spending by sales in order to control for the fact that large firms spend more on R\&D. We used sales and R\&D spending data from the year of IPO because once a firm goes public it undergoes both a quantitative (from the infusion of cash) and qualitative transformation that renders prior spending and revenue levels less reflective of the firm in its post-IPO form. We then take the natural logarithm of this variable plus unity to correct for skewness in its distribution. We use the variable plus unity because a small number of firms had zero sales.

Stock price at IPO. Stock price at IPO was used to control for prior firm performance. When a firm goes public the initial price is set based on prior performance and potential performance (see Ibbotson \& Ritter, 1995, for additional discussion of IPO pricing). As such, the initial price of a firm's stock should impact its future performance. Stock price at IPO is a better indicator of prior performance for this sample than profits because at the time of IPO firms may have operating losses or zero profits. Stock price at IPO is measured as the offer price listed in the prospectus (this measure correlates $r=0.97, p<0.001$ with a measure of the offer price as reported in Going Public: The IPO Reporter).

Silicon Valley. We controlled for the location of firm headquarters because firms embedded in a regional nexus of innovating (and patenting) are more likely to innovate due to knowledge spillover effects and intraregional personnel movement. These firms may also perform better for similar reasons. Saxenian (1994) has documented such activity in California's Silicon Valley. Almeida and Kogut (1999) studied engineer mobility in regional networks and found that 'only Silicon Valley exhibits strong localization effects' (p. 912). That is, knowledge in Silicon Valley tends to stay in Silicon Valley and, in order to capitalize on the externalities of such knowledge, firms must locate in Silicon Valley and become part of the regional network. Therefore, a control is included for whether or not the firm is headquartered in Silicon Valley ( 1 if yes, 0 otherwise). We do not include additional dummy variables for other regional hubs (e.g., Austin, Minneapolis, North Carolina's Research Triangle, Boston's Route 128 , and New York's Silicon Alley) that may exhibit similar properties because these firms either comprise a much smaller portion of the sample, or these hubs had yet to emerge as of the period under study. Controlling for location in Silicon Valley is also essential given the size of the firms in our sample. Acs, Audretsch, and Feldman (1994) have found that small firms benefit disproportionately from spillovers from universities and larger firms. 
SIC code. Although both the SIC codes used to comprise our sample were chosen for their contribution to innovation and patenting, it is possible that firms in a given industry classification have a greater propensity to patent. Therefore, we control for SIC code using a dummy variable ( 1 = SIC 7372; prepackaged software). Data regarding a firm's primary SIC code was obtained from CRSP.

Period effects. Using four cohorts of IPO software firms (1993, 1994, 1995, and 1996) to test our hypotheses provides a more robust test. However, each period can have particular effects that bias the estimators and remain unaccounted for in other variables. Thus, period effects were controlled using three dummy variables for the year of IPO (1994, 1995, and 1996) with 1993 as the base line category. A firm was coded as belonging to the year in which it went public as indicated in Going Public: The IPO Reporter.

\section{Results}

The descriptive statistics and correlation matrix can be seen in Table 1. The most noteworthy descriptive statistic is the significantly inflated value of R\&D intensity. This inflation results from three outliers that have R\&D intensities greater than 100. These outliers are 'development stage' firms that have extremely low revenue. Without these three observations the mean is $0.28(\mathrm{SD}=0.60)$. The median of 0.17 also presents a more accurate picture of representative levels of R\&D intensity. We include these observations in both the correlations and in our regression analyses for two reasons: first, the impact of the outliers is reduced by taking the natural logarithm of R\&D intensity; and second, the results remain substantively similar with or without the observations. The correlation matrix indicates that the variables are largely uncorrelated. The absence of strong correlations between the variables minimizes the risk of multicollinearity.

To test Hypotheses 1 through 3 we utilized zero-inflated Poisson regression. Count models such as Poisson regression and negative binomial regression have a long history in analysis of patent data (Griliches, 1990). The use of software patents as a dependent variable poses some unique problems because some firms do not attempt to patent as a matter of strategy, ideology, or other reasons. This empirical reality is problematic for a standard Poisson regression because it will under-predict the number of zeros and fail to distinguish between a firm that tries to patent but fails from a firm that does not try. The zero-inflated method explicitly assumes that zeros occur through two processes: (1) always has a zero count, for example, a firm that believes patents are too costly and thus does not file a patent application; and (2) has zeros by chance, for example, a firm that tries to patent an innovation, but the patent is rejected. The zero-inflated Poisson allows the probability of always being zero $\left(\Psi_{\mathrm{i}}\right)$ to be determined by characteristics of the firm using a logistic regression (Long, 1997). For those firms not always zero, counts are determined by combining the binary process (the probability of not remaining at zero, $1-\Psi_{\mathrm{i}}$ ) and a Poisson count model. The full model for the firms that are not always zero is

$$
\operatorname{Pr}\left(y_{\mathrm{i}} \mid x_{\mathrm{i}}\right)=\left(1-\Psi_{\mathrm{i}}\right) \frac{\exp \left(-\mu_{\mathrm{i}}\right) \mu_{\mathrm{i}}^{y \mathrm{i}}}{y_{\mathrm{i}} !}
$$

where $1-\Psi_{\mathrm{i}}$ is the probability of not always having a zero count as estimated using characteristics of the firm and $\exp \left(-\mu_{\mathrm{i}}\right) \mu_{\mathrm{i}}^{y \mathrm{i}} / y_{\mathrm{i}}$ ! is a Poisson process where $\mu=\exp (x B)$ and $x B$ is a vector of firm characteristics (Long, 1997). The zero-inflated Poisson models were estimated using Stata 7.0. 
Table 2. Regression analyses of patent counts and stock price

\begin{tabular}{|c|c|c|c|}
\hline \multirow[b]{2}{*}{ Variable } & \multirow{2}{*}{$\begin{array}{c}\text { Patent count } \\
\text { Model } 1\end{array}$} & \multicolumn{2}{|c|}{ Stock price } \\
\hline & & Model 2 & Model 3 \\
\hline \multicolumn{4}{|l|}{ Independent variables } \\
\hline Training & $0.72 * * *(3.54)$ & $-0.05(-0.28)$ & $-0.07(1.46)$ \\
\hline Employee relations - excellent & $2.47 * *(2.71)$ & $-0.80^{\dagger}(-1.76)$ & $-0.84 *(-1.85)$ \\
\hline Employee relations - very good & $-20.16(-0.00)$ & $1.00^{\dagger}(1.32)$ & $1.01^{\dagger}(1.34)$ \\
\hline Employee relations - good & $1.67 *(2.00)$ & $-0.35(-1.11)$ & $-0.35(-1.11)$ \\
\hline Temporary employees & $1.00 * * *(3.67)$ & $0.07(0.27)$ & $0.02(0.10)$ \\
\hline \multicolumn{4}{|l|}{ Mediating variable } \\
\hline Post-IPO patent count & & & $0.04^{\dagger}(1.46)$ \\
\hline \multicolumn{4}{|l|}{ Control variables } \\
\hline Patents at IPO & $-0.00(-0.06)$ & & \\
\hline $\mathrm{R} \& \mathrm{D} /$ sales & $0.09 *(2.39)$ & & \\
\hline Firm HQ in Silicon Valley & $0.04(0.20)$ & $0.08(0.42)$ & $0.05(0.29)$ \\
\hline Firm size at IPO ${ }^{\mathrm{a}}$ & $0.24^{\dagger}(1.93)$ & $0.27 *(2.22)$ & $0.27 *(2.40)$ \\
\hline Firm age at $\mathrm{IPO}^{\mathrm{a}}$ & $-0.65 * * *(-6.20)$ & $-0.08(-0.79)$ & $-0.06(-0.60)$ \\
\hline Stock price at IPO & & $0.11 * * *(5.05)$ & $0.10 * * *(4.36)$ \\
\hline SIC Code ${ }^{b}$ & $1.16^{* *}(2.89)$ & $0.03(0.14)$ & $0.02(0.10)$ \\
\hline \multicolumn{4}{|l|}{ Period effects (1993 IPO baseline) } \\
\hline 1996 IPO & $0.18(0.53)$ & $-0.63 *(-2.26)$ & $-0.60 *(-2.17)$ \\
\hline 1995 IPO & $0.99 * * *(3.46)$ & $-0.53^{\dagger}(-1.90)$ & $-0.50^{\dagger}(-1.83)$ \\
\hline 1994 IPO & $1.03 *(2.30)$ & $-0.24(-0.72)$ & $-0.22(-0.65)$ \\
\hline Chi-square & $128.50 * * *$ & & \\
\hline$F$ & & $6.23 * * *$ & $5.98 * * *$ \\
\hline$R^{2}$ & 0.32 & 0.33 & \\
\hline$\Delta R^{2}$ & & & $0.01 * *$ \\
\hline$N$ & 184 & 184 & 184 \\
\hline
\end{tabular}

The results of our regression analyses are reported in Table 2. In the first model we utilize the zeroinflated Poisson to estimate the expected number of post-IPO patents. The overall equation is significant (chi-square $=128.50, p<0.001$ ). Next, we performed a Vuong test for non-nested models to determine whether the zero-inflated model was a better fit for the data than a standard Poisson regression. The Vuong test generates a test statistic that has a standard normal distribution with large positive values favoring the zero-inflated model and with large negative values favoring the non-zero-inflated version (Long, 1997). Values close to zero in absolute value favor neither model. For Model 1 in Table 2 the Vuong statistic is $2.47(p<0.01)$, indicating the zero-inflated model is a better fit. This empirically confirms the assertion that failing to patent in the software industry is a result of two distinct processes of either not trying to patent or trying and failing.

We modeled the probability of remaining at zero using two independent variables: patents prior to IPO and being headquartered in Silicon Valley. The results (not reported in Table 2) indicate that both significantly predict the probability of a firm remaining at zero patents. Firms with patents prior to IPO are less likely to have zero patents after IPO $(B=-1.04, p<0.001)$. In other words, for each additional patent prior to IPO the odds of a firm not patenting after IPO are decreased 65 per cent. Firms headquartered in Silicon Valley are also significantly less likely to have zero patents after IPO 
$(B=-1.12, p<0.05)$ as being headquartered in Silicon Valley reduces the likelihood of not patenting after IPO by 67 per cent. We also tested numerous other specifications in this portion of the model, but the pattern of results was substantively similar and no other variables were statistically significant in predicting the probability of a firm remaining at zero patents. Thus, we utilized the more parsimonious model.

We evaluate our hypotheses using the count portion of Model 1. All findings in the count portion of Model 1 should be interpreted as only applying to those firms at risk of patenting (i.e., not including the firms that will never attempt to patent due to ideological, strategic, or other reasons). Hypothesis 1 proposed that firms using skilled temporary employees would produce more innovations and was strongly supported $(B=1.00, p<0.001)$. In other words, for firms at risk of patenting, using skilled temporary employees increases the expected number of patents by a factor of 2.72 or 272 per cent, holding all other variables constant. Hypothesis 2 asserted that firms possessing positive (excellent, very good, or good) employee relations would innovate more than firms with negative (satisfactory) employee relations. Our findings partially support Hypothesis 2, as firms at risk of patenting with either excellent $(B=2.40, p<0.01)$ or $\operatorname{good}(B=1.67, p<0.05)$ employee relations were significantly associated with greater intensity of innovation than firms with satisfactory employee relations (the baseline category). The effect of employee relations is especially pronounced as firms at risk of patenting with excellent employee relations increase their expected number of patents by a factor 11.07 or 1107 per cent and firms at risk of patenting with good employee relations increase their number of patents by a factor of 5.31 or 531 per cent relative to satisfactory employee relations, holding all other variables constant. However, for firms at risk of patenting, very good employee relations $(B=-20.16$, n.s.) were not associated with greater innovative output than firms with satisfactory employee relations. Although very good employee relations exhibited no relationship with the expected number of post-IPO patents, this non-finding should be taken with caution as only 3 (1.63 per cent) of the 184 firms in our sample reported very good employee relations. Thus, the lack of support may be an artifact of the small number of observations for very good employee relations. Lastly, Hypothesis 3 posited that an emphasis on training would lead to greater intensity of innovation. Hypothesis 3 receives strong support as an emphasis on training $(B=0.73, p<0.001)$ for firms at risk of patenting is significantly related to the expected number of post-IPO patents. In real terms, firms at risk of patenting with an emphasis on training increase their expected number of patents by a factor of 2.07 or 207 per cent, holding all other variables constant. Overall, when a firm at risk of patenting combines the use of skilled temporary employees, excellent employee relations, and an emphasis on training with the rest of the variables held at their mean, the expected count is 5.1 patents and these firms have a 32 per cent probability of having more than three patents after their IPO. This is a marked increase over the expected count of 0.46 and 0.4 per cent probability of having greater than three patents in a firm at risk of patenting where all variables are held at their mean. In a firm at risk of patenting where all the variables of interest are held at zero, the results are even starker as the expected count is 0.08 and there is only a 2.8 per cent probability of having more than zero post-IPO patents. From these results we conclude that the use of skilled temporary employees, positive employee relations, and an emphasis on training strongly increase innovative output by IPO software firms.

Among the control variables it is interesting to note that neither being headquartered in Silicon Valley nor patenting prior to IPO significantly influences the expected count of patents after IPO. It seems these variables only influence a firm's decision to attempt to patent and not necessarily their success in doing so. One other result worth mentioning is the strong negative relationship between firm age $(B=-0.65, p<0.001)$ and the expected count of post-IPO patents. This finding contradicts Sorensen and Stuart's (2000) finding that older firms patent more frequently. However, our finding should not be taken as decisive because it may be a function of the sample and the industry. The older firms in our sample may not patent because patenting software was not common practice until the mid 1990s. Prior 
to this time copyright was the default mode of intellectual property protection. Consequently, firms with established routines for copyrighting may have had difficulty transitioning to the much more complex and costly process of filing patents. Thus, our anomalous finding suggests that the relationship between firm age and patenting may be contingent upon the imprinting that occurred during the era of a firm's founding (Stinchcombe, 1965).

To test Hypothesis 4, that the proposed mediator (number of post-IPO patents) mediates the effects of the independent variables (using skilled temporary employees, positive employee relations, and an emphasis on training) on the dependent variable (stock price), we conducted a three-stage analysis to test whether the following three criteria for mediation were met: (1) the three HR practice variables affect post-IPO patents (Model 1); (2) the three HR practice variables affect stock price 3 years after IPO (Model 2); and (3) the number of post-IPO patents affect stock price 3 years after IPO (Model 3). If these three conditions are met and in the predicted direction, the final requirement for mediation is that the effect of contribution of the three HR practice variables on stock price 3 years after IPO either decreases (partial mediation) or becomes insignificant ('perfect mediation') between Model 2 and Model 3 (Baron \& Kenny, 1986, p. 1177). We tested for mediation using ordinary least squares (OLS) regression analyses by regressing the log of stock price 3 years after IPO on the independent, mediating, and control variables. The first condition, that the three HR practice variables significantly affect the number of post-IPO patents, is strongly supported in Model 1. The test for the second condition of mediation is shown in Model 2 of Table 2. The results do not support this condition of mediation as an emphasis on training $(B=-0.05$, n.s.), the use of skilled temporary employees $(B=0.07$, n.s.), and good employee relations $(B=-0.35$, n.s.) have no relationship with the dependent variable, while the effect of excellent employee relations' $(B=-0.80, p<0.10)$ is in the opposite direction of what we predicted. The lone exception is very good employee relations $(B=1.00, p<0.10)$, which had a moderately significant positive effect on stock price 3 years after IPO, relative to satisfactory employee relations. As previously discussed, in order to test for the third condition of mediation we measured the proposed mediator as the number of patents granted prior to the end of the third year after IPO. Lastly, the data tenuously support the third criterion for mediation as the number of post-IPO patents has a significant positive effect on stock price $(B=0.04, p<0.10)$ and on the overall fit of the model $\left(\Delta R^{2}=0.01, F=2.13, p<0.01\right)$. Given that condition 2 of mediation was not met and condition 3 only received marginal support, Hypothesis 4 receives no support. We discuss this unexpected finding in more detail in the discussion section. Different specifications of the dependent variable (e.g., difference score, per centage change) yielded substantively similar results.

\section{Discussion}

Two questions motivated this study: Under what conditions do ordinary organizations resemble HROs? How do firms organize to replicate the extraordinary performance of HROs? First, we proposed that firms become reliability seeking to the extent that their organization-environment relations are interactively complex and tightly coupled. Second, we argued that three HR practices - use of skilled temporary employees, positive employee relations, and an emphasis on training - generate innovation through the theorized, but unmeasured, processes of collective mindfulness. The quantitative analyses strongly supported the hypothesized relationships as all three HR practices substantially increased innovation, which, in turn, increased stock price 3 years after IPO.

We proposed that skilled temporary employees complicate existing mindsets and maintain divergent perspectives that foster innovation. Qualitative data from our sample provides some additional support 
for our theoretical claim that each HR practice enables and generates innovation via a process of collective mindfulness. For example, one firm argues that having skilled temporary employees is a way to access unique and valuable skills they might not otherwise be able obtain or build due to the prohibitive costs that a small software firm has difficulty bearing. Another firm similarly argues, 'the most innovative and successful new software products are likely to be generated by independent developers ... [using independent contractors] will result in [the company] having access to talented independent developers without the overhead and administrative structure.'

Second, we theorized that positive employee relations enable innovation by way of intensive communication and sensitivity to ongoing operations. Qualitative data from a firm with excellent employee relations provides suggestive support for this claim as its supportive climate fosters 'honest, open and ethical dealings' and real-time information sharing across levels. An additional press account (Petzinger, 1997) indicated that this same firm goes to additional lengths to construct an accurate picture of operations in the moment through real-time information sharing as it utilizes a system where all employees file regular personal-action reports that identify major obstacles to their work. Everyone's report is subsequently posted electronically for everyone else's inspection. This system keeps real-time information flowing and enhances the possibility for innovative solutions to problems because all problems are being shared with all parties.

Third, we theorized that an emphasis on training creates a commitment to resilience and builds the requisite cognitive and behavioral resources to manage growth and improvise solutions in an everchanging environment. One firm notes that it 'trains its professionals in both legacy systems and emerging technologies' and thereby endows them with the skills to cope with many potential states of the environment. A different firm similarly notes 'the Company has an extensive training infrastructure... trains employees on a variety of platforms and helps them transition from legacy to client/server skills by providing cross-platform training in new technologies.' This quote emphasizes how training helps upgrade skills so individuals feel as though they are broadly skilled and, subsequently, can attend to a wider variety of inputs (Weick, 1988).

Hypothesis 4, suggesting that innovation mediates the effect of the HR practices on firm performance, was not supported. While this finding is partially consistent with a reliability-efficiency trade-off, whereby HR practices have their greatest impact on more proximate measures of performance, it merits further exploration in future studies. One possible explanation for our finding is that the 3-year lag between when the HR practices and stock price are measured may be too long an interval. The efficient market hypothesis (Fama, 1970) posits that the stock market reacts to new information. Thus any impact of HR practices on stock price would occur relatively shortly after they were implemented. Furthermore, the HR practices are measured at one point in time, IPO. It is possible that these practices may have changed over time and these new practices may not have been as well received and yielded no stock price benefit. The negative relationship between excellent employee relations and stock price 3 years after IPO may result from the fact that investors often view generous employee relations as costly and excessive slack and thus punish these firms for operating inefficiently with a lower share price (Jensen, 1993).

Another possibility, however, is that firm survival may be a better indicator of the longer-term and less proximate benefits that can arise from collective mindfulness and the ability to manage the unexpected. Using the full sample of 269 firms we crudely tested whether these HR practices had an impact on firm survival 3 years after IPO. We used a logistic regression $(1=$ firm left the sample, 0 otherwise $)$ with all the independent and control variables included in Model 3 of Table 2. The results (not reported) indicate that training significantly reduced the likelihood of exiting the sample (i.e., increased the likelihood of 'survival'). Firms with an emphasis on training and all other variables held at their mean are 13 per cent more likely to survive than the mean firm $(93$ per cent versus 80 per cent survival rate). Skilled temporary employees and positive employee relations had no effect on survival. 
However, these results should be taken as extremely tentative because our measure of firm exit does not differentiate between bankruptcy, merger/acquisition, delisting, or going private. It is likely that each of these forms of exit occurs under qualitatively different circumstances. Even with the significant impact of an emphasis on training on firm survival, the overall pattern of results still indicates that HR practices have their strongest impact on more proximate outcomes like innovation.

This study has significant implications for work in the areas of high reliability and collective mindfulness as it suggests two potential boundary conditions and future research directions. We argued that HR practices work through mindfulness and our findings suggest the beginnings of taxonomy of ordinary HR practices that may enable and shape mindful processing. Future work should explore additional practices and enabling conditions of mindfulness. Our results, when coupled with prior work on HROs, also suggest an interesting boundary condition for collective mindfulness - size. The majority of the firms in the sample had fewer than 200 employees, allowing them to operate much more like an operating unit (e.g., an aircraft carrier flight deck, an air traffic control tower) than a large firm. Future work will need to untangle under what conditions collective mindfulness is beneficial for an entire organization. That is, do all parts of the organization need to engage in mindful processing at all times? In a small entrepreneurial venture where errors of omission are frequently fatal, the answer is likely 'yes,' but in an organization with substantial slack, mindfulness could be utilized on an exception basis. Furthermore, collective mindfulness might only need to be present in 'core' areas (especially when the outcome of interest is at the operating level, be it innovation or safe operations) - which may explain why it seems to be (and needs to be) omnipresent in operations-centric organizations such as air traffic control, nuclear power operations, and nuclear aircraft carriers.

Our findings and theorizing also suggest several possible refinements for the strategic human resource management literature. First, the findings suggest a more parsimonious and theoretically driven set of mechanisms for achieving greater intensity of innovation as opposed to long lists of practices that characterize many strategic human resource management studies (e.g., Huselid, 1995). The value of parsimony is enhanced in dynamic environments because discontinuous change and unclear causeeffect relationships make a mindful approach more tenable than attempting fit because the complexity of these environments precludes sufficient knowledge to accurately fit an environment at a given moment. In such environments, fit may even be maladaptive as it generates conditions of tight coupling, which preclude adaptability (Becker \& Gerhart, 1996).

Second, our results suggest that the HR practices that contribute to performance do not apply in all contexts and may vary across sector or industry. For example, in the petrochemical (Kochan et al., 1992), mining, and construction (Rousseau \& Libuser, 1997) industries, using temporary employees significantly diminished reliability and performance, but this same practice significantly enhanced the number of innovations produced by the firms in our sample. This suggests the need for a multi-industry study that explores in more depth when and how different HR practices are relevant for mindfulness, reliability, and performance.

Third, the results suggest an alternate set of mechanisms for unpacking the HR practice-firm performance relationship. Prior research has emphasized the role of discretionary effort (e.g., MacDuffie, 1995). In contrast, based on the results of this study we suggest that HR practices that foster intimate knowledge (reluctance to simplify), situational awareness (information sharing and sensitivity to operations), and recovery skills (resilience) should promote innovation and performance. ${ }^{3}$ The processes encouraged by HR practices may also mediate their relationship with firm performance and merits further investigation. Lastly, HR practices seem to have their greatest impact on more proximate measures of firm performance (i.e., innovation) as opposed to more distant financial measures such as stock price. This finding is consistent with previous studies that found a strong relationship between

${ }^{3}$ We thank Karl Weick for suggesting this argument. 
HR practices and operating performance in manufacturing (Ichniowski et al., 1997; MacDuffie, 1995) and that failed to find a similarly strong relationship between HR policies and stock price (Welbourne \& Andrews, 1996; Hannon \& Milkovich, 1996).

\section{Limitations}

The findings of this study must be considered in light of its limitations. First, because our study consisted of one industry, the results of this study may be idiosyncratic to IPO software firms and, therefore, not generalizable. We attempted to ameliorate the generalizability issue by theorizing that firms become reliability seeking based on the extent to which their environments are interactively complex and tightly coupled. Our theoretical analysis suggests that IPO software firms meet these criteria. A wider array of organizations may also meet these criteria as interconnected technologies and resource demands move many organizations toward a more tightly coupled and interactively complex state (Weick \& Sutcliffe, 2001). Thus, to the extent that an industry or firm faces a similarly unforgiving environment, a wider variety of firms may be reliability seeking and the processes of collective mindfulness should apply.

Second, while our use of the zero-inflated Poisson is appropriate given the fact that some firms may never attempt to patent, it also circumscribes the generalizability of our findings. We have acknowledged this limitation by discussing our results as only holding for firms at risk of patenting (i.e., not structurally zero). However, this limitation remains potentially problematic to the extent that innovative firms do not patent. If innovative firms do not patent then our results cannot be read as supporting a relationship between HR practices and innovation generally, but only between HR practices and patents. While we cannot definitively determine whether there are sufficient innovative firms that do not patent to bias our results, we believe this is not the case. First, data from the Software Encyclopedia (1999), which summarizes industry analyst reviews of 'most innovative' and 'best software applications,' indicates that the firms with the highest patent counts (e.g., Netscape Communications, i2, and Macromedia) were also ranked as most innovative. Furthermore, prior empirical work by Flood et al. (1997) found that for a sample of high-technology firms patenting significantly correlated with innovative 'pioneering' behavior (i.e., the capacity of the firm to develop new products ahead of rivals).

A third limitation of this study is sample selection bias and survivor bias. By studying IPO firms, we exclude software firms that choose not to go public (e.g., the SAS Institute) as well as firms that may cease operations prior to undertaking an IPO. This problem is further exacerbated by survivor bias because older firms and smaller firms (both significant at $p<0.001$ ) are more likely to be excluded from the analysis due to a merger/acquisition, delisting, or bankruptcy prior to 3 years after IPO. The survivor bias is a result of implementing a panel design, which regresses firm outcomes at $t_{3}$ on firm variables at $t_{0}$. While both of these issues are problematic, they are outweighed by the fact that the panel design allows us to adequately test our hypotheses. Most importantly, a cross-sectional design would not allow us to observe the intensity of innovation over a meaningful period of time (i.e., 3 years).

Lastly, we utilized binary indicators for our HR practices and the exact processes of collective mindfulness remain unmeasured. While our limited qualitative data and the extant literature provides suggestive support for our theorizing of underlying processes, only a handful of the firms in our sample make an even marginally detailed statement regarding the content of their practices. Thus, our measures still suffer from the fact that they do not directly correspond to the theoretical processes posited. Ideally, we would have more exact measures of both HR practices and mindful processes to better assess the form of the relationships between these constructs. Therefore, the results should serve as a foundation for grounded fieldwork or surveys that more explicitly and extensively examines the processes of collective mindfulness as well as the relationship between HR practices and mindfulness. 


\section{Conclusion}

HROs have long been viewed as 'too exotic' to offer insight into high performance in other organizations (Scott, 1994). We have challenged this view and asserted that while ordinary organizations may not operate high-hazard technologies, they may face the same conditions of tight coupling and interactive complexity when interacting with their external environments. Thus, even ordinary organizations may be reliability seeking. The results of this study indicate that three HR practices (the use of skilled temporary employees, positive employee relations, and an emphasis on training) help a subset of reliability-seeking organizations (IPO software firms) achieve innovation. While we indirectly test the processes of collective mindfulness, our findings suggest its structural underpinnings. Given the results of this study, this merits additional attention. Future research should use both HR practices and the collective mindfulness framework to study an even wider variety of settings to better assess the relationships between structures and processes as well as the scope and boundary conditions of mindfulness.

\section{Acknowledgements}

We are especially grateful to Kathie Sutcliffe for her ongoing encouragement, insightful criticisms, and helpful suggestions. We also thank Jerry Davis, Jane Dutton, Emily Heaphy, Katherine Lawrence, Fiona Lee, Scott Long, Nick Turner, Jenny Vogus, Jerry Vogus, Susan Vogus, Klaus Weber, Karl Weick, Julia Welch, and the participants of the Organizational Behavior Brown Bag at the University of Michigan for comments that significantly improved this manuscript, and Meghann Kelley for invaluable help with data collection. We would also like to thank Mary Waller and the journal's anonymous reviewer for constructive and thoughtful comments that both significantly tightened the focus and increased the clarity of the manuscript.

\section{Author biographies}

Timothy J. Vogus is a doctoral candidate in Organizational Behavior and Human Resource Management at the University of Michigan Business School. His research interests include strategic human resource management, collective cognition and sensemaking, and high-reliability organizing. He particularly focuses on the interplay of organizational structures and cognitive processes in creating and sustaining high performance. He also studies the cognitive and political dynamics of institutional emergence and change.

Theresa M. Welbourne is Associate Professor of Organization Behavior and Human Resource Management at the University of Michigan Business School and the founder, President, and CEO of eePulse, Inc. She received her PhD in business (HRM) from the University of Colorado, Boulder. Her current research interests are in the areas of employee management in highgrowth and high-change organizations. Her particular focus is on understanding how various human resource strategies affect the longer-term performance of organizations and the employees within those firms. 


\section{References}

Abowd, J. M., Milkovich, G. T., \& Hannon, J. M. (1990). The effect of human resource management decisions on shareholder value. Industrial and Labor Relations Review, 43, 203S-236S.

Acs, Z. J., Audretsch, D. B., \& Feldman, M. (1994). R\&D spillovers and recipient firm size. Review of Economics and Statistics, 76, 336-340.

Ahuja, G. (2000). Collaboration networks, structural holes, and innovation: a longitudinal study. Administrative Science Quarterly, 45, 425-455.

Aldrich, H. E. (1999). Organizations Evolving. Thousand Oaks, CA: Sage.

Aldrich, H. E., \& Pfeffer, J. (1976). Environments of organizations. Annual Review of Sociology, 2, 79-105.

Almeida, P., \& Kogut, B. (1999). Localization of knowledge and the mobility of engineers in regional networks. Management Science, 45, 905-917.

Arthur, J. B. (1992). The link between business strategy and industrial relations systems in American steel minimills. Industrial and Labor Relations Review, 45, 488-506.

Baron, R. S., \& Kenny, D. A. (1986). The moderator-mediator distinction in social psychological research: conceptual, strategic and statistical considerations. Journal of Personality and Social Psychology, 51, 1173-1182.

Becker, B., \& Gerhart, B. (1996). The impact of human resource management on organizational performance: progress and prospects. Academy of Management Journal, 39, 779-801.

Bogner, W. C., \& Barr, P. S. (2000). Making sense in hypercompetitive environments: a cognitive explanation for the persistence of high velocity competition. Organization Science, 11, 212-226.

Bourgeois, L. J., \& Eisenhardt, K. M. (1988). Strategic decision processes in high velocity environments: four cases in the microcomputer industry. Management Science, 34, 816-835.

Brown, S. L., \& Eisenhardt, K. M. (1995). Product development: past research, present findings, and future directions. Academy of Management Review, 20, 343-378.

Brown, S. L., \& Eisenhardt, K. M. (1997). The art of continuous change: linking complexity theory and timepaced evolution in relentlessly shifting organizations. Administrative Science Quarterly, 42, 1-34.

Cockburn, I. M., \& Griliches, Z. (1988). Industry effects and appropriability measures in the stock market's valuation of R\&D and patents. American Economic Review, 78, 419-423.

Cockburn, I. M., \& Henderson, R. M. (1998). Absorptive capacity, coauthoring behavior, and the organization of research in drug discovery. Journal of Industrial Economics, 46, 157-183.

Creed, W. E. D., Stout, S. K., \& Roberts, K. H. (1993). Organizational effectiveness as a theoretical foundation for research on reliability-enhancing organizations. In K. H. Roberts (Ed.), New challenges to understanding organizations (pp. 55-73). New York: Macmillan.

D'Aveni, R. (1994). Hypercompetition: Managing the dynamics of strategic maneuvering. New York: Free Press.

Deng, Z., Lev, B., \& Narin, F. (1999). Science and technology as predictors of stock performance. Financial Analysts Journal, 55, 20-32.

Eisenhardt, K. M. (1989). Making fast strategic decisions in high-velocity environments. Academy of Management Journal, 32, 543-576.

Eisenhardt, K. M., \& Tabrizi, B. N. (1995). Accelerating adaptive processes: product innovation in the global computer industry. Administrative Science Quarterly, 40, 84-110.

Erickson, J. (1999). Software patents con. Dr. Dobb's News and Views, 1 January, 18.

Fama, E. F. (1970). Efficient capital markets: a review of theory and empirical work. Journal of Finance, 25, 383-417.

Flood, P. C., Fong, C. M., Smith, K. G., O’Regan, P., Moore, S., \& Morley, M. (1997). Top management teams and pioneering: a resource-based view. International Journal of Human Resource Management, 8, 291-306.

Gaba, D. M. (2000). Structural and organizational issues in patient safety: a comparison of health care to other high-hazard industries. California Management Review, 43, 83-102.

Griliches, Z. (1990). Patent statistics as economic indicators: a survey. Journal of Economic Literature, 28, 1661-1707.

Hambrick, D. C., \& Crozier, L. M. (1985). Stumblers and stars in the management of rapid growth. Journal of Business Venturing, 1, 31-45.

Hannan, M. T., \& Freeman, J. (1984). Structural inertia and organizational change. American Sociological Review, 49, 149-164.

Hannan, M. T., \& Freeman, J. (1989). Organizational ecology. Cambridge, MA: Harvard University Press. 
Hannon, J. M., \& Milkovich, G. T. (1996). The effect of human resource reputation signals on share prices: an event study. Human Resource Management, 35, 405-424.

Hausman, J. A., Hall, B. H., \& Griliches, Z. (1984). Econometric models for count data with an application to the patents-R\&D relationship. Econometrica, 52, 909-938.

Huselid, M. A. (1995). The impact of human resource management practices on turnover, productivity, and corporate financial performance. Academy of Management Journal, 38, 635-672.

Ibbotson, R. G., \& Ritter, J. R. (1995). Initial public offerings. In R. A. Jarrow, V. Masksimovic, \& W. T. Ziemba (Eds.), Finance (pp. 993-1016). Amsterdam: Elsevier Science.

Ichniowski, C., Shaw, K., \& Prennushi, G. (1997). The effects of human resource management practices on productivity: a study of steel finishing lines. American Economic Review, 87, 291-313.

Jarmon R., Paulson, A. S., \& Rebne, D. (1998). Contractor performance: how good are contingent workers at the professional level? IEEE Transactions on Engineering Management, 45, 11-19.

Jensen, M. C. (1993). The modern industrial revolution, exit, and the failure of internal control systems. Journal of Finance, 48, 831-880.

Kalleberg, A. (2000). Nonstandard employment relations: part-time, temporary and contract work. Annual Review of Sociology, 26, 341-365.

Kochan, T. A., Wells, J. C., \& Smith, M. (1992). Consequences of a failed IR system: contract workers in the petrochemical industry. Sloan Management Review, 21, 79-89.

Langer, E. J. (1989). Mindfulness. Cambridge, MA: Perseus.

Langer, E. J. (1997). The power of mindful learning. Cambridge, MA: Perseus.

LaPorte, T. R. (1996). High reliability organizations: unlikely, demanding and at risk. Journal of Contingencies and Crisis Management, 4, 60-71.

LaPorte, T. R., \& Consolini, P. M. (1991). Working in practice but not in theory: theoretical challenges of 'high reliability organizations'. Journal of Public Administration Research and Theory, 1, 19-47.

Lee, F., Hallahan, M., \& Herzog, T. (1996). Explaining real-life events: how culture and domain shape attributions. Personality and Social Psychology Bulletin, 22, 732-741.

Levesque, L. L., Wilson, J. M., \& Wholey, D. R. (2001). Cognitive divergence and shared mental models in software development project teams. Journal of Organizational Behavior, 22, 135-144.

Long, J. S. (1997). Regression models for categorical and limited dependent variables. Thousand Oaks, CA: Sage.

March, J. G. (1991). Exploration and exploitation in organizational learning. Organization Science, 2, $71-87$.

MacDuffie, J. P. (1995). Human resource bundles and manufacturing performance: organizational logic and flexible production systems in the world auto industry. Industrial and Labor Relations Review, 48, 147-169.

Nemeth, C. J. (1986). Differential contributions of majority and minority influence. Psychological Review, 93, 23-32.

Nemeth, C. J. (1997). Managing innovation: when less is more. California Management Review, 40, 59-74.

Nemeth, C. J., \& Kwan, J. L. (1985). Originality of word associations as a function of majority vs. minority influence. Social Psychology Quarterly, 48, 277-282.

Nemeth, C. J., \& Staw, B. M.. (1989). The tradeoffs of social control and innovation in groups and organizations. In L. Berkowitz (Ed.), Advances in experimental social psychology (Vol. 22, pp. 175-210). San Diego, CA: Academic Press.

Nichols, K. (1998). Inventing software: The rise of 'computer related' patents. Westport, CT: Quorum.

O'Flaherty, J. S. (1984). Going public: The entrepreneur's guide. New York: Wiley.

Perron, M. J., \& Friedlander, R. H. (1996). The effects of downsizing on safety in the CPI/HPI. Process Safety Progress, 15, 18-25.

Perrow, C. (1999). Normal accidents: Living with high-risk technologies (2nd edn). Princeton, NJ: Princeton University Press.

Petzinger, T. (1997). The front lines: Bob Felton hates bureaucracy, loves a staff that talks. Wall Street Journal, 10 January, B1.

Pfeffer, J. (1994). Competitive advantage through people: Unleashing the power of the work force. Boston, MA: Harvard Business School Press.

Pfeffer, J. (1998). The human equation: Building profits by putting people first. Boston, MA: Harvard Business School Press.

Powell, W. W., Koput, K. W., Smith-Doerr, L. (1996). Interorganizational collaboration and the locus of innovation: networks of learning in biotechnology. Administrative Science Quarterly, 41, 116-145.

Roberts, K. H. (1990). Some characteristics of high-reliability organizations. Organization Science, 1, $160-177$.

Roberts, K. H., \& Libuser, C. (1993). From Bhopal to banking: organizational design can mitigate risk. Organizational Dynamics, 21(4), 15-28. 
Roberts, K. H., Stout, S. K., \& Halpern, J. J. (1994). Decision dynamics in two high reliability organizations. Management Science, 40, 614-624.

Rochlin, G. I., LaPorte, T. R., \& Roberts, K. H. (1998). The self-designing high-reliability organization: aircraft carrier flight operations as sea. Naval War College Review, 51, 97-113.

Rousseau, D. M., \& Fried, Y. (2001). Location, location, location: contextualizing organizational research. Journal of Organizational Behavior, 22, 1-13.

Rousseau, D. M., \& Libuser, C. (1997). Contingent workers in high risk environments. California Management Review, 39, 103-123.

Saxenian, A. (1994). Regional advantage: Culture and competition in Silicon Valley and Route 128. Cambridge, MA: Harvard University Press.

Schulman, P. R. (1993). The negotiated order of organizational reliability. Administration and Society, 25, 353-372.

Schulman, P. R. (2002). Medical errors: how reliable is reliability theory? In M. M. Rosenthal, \& K. M. Sutcliffe (Eds.), Medical error: What do we know? Where do we need to go? (pp. 200-216). San Francisco: Jossey-Bass.

Shulman, S. (2000). Software patents tangle the web. Technology Review, 66-76.

Scott, W. R. (1994). Open peer commentaries on 'accidents in high-risk systems'. Technology Studies, 1, 23-25. Software encyclopedia. (1999). New York: R. R. Bowker.

Sorensen, J. B., \& Stuart, T. E. (2000). Aging, obsolescence and organizational innovation. Administrative Science Quarterly, 45, 81-112.

Steinmueller, W. E. (1996). The U.S. software industry: an analysis and interpretive history. In D. C. Mowery (Ed.), The international computer software industry: A comparative study of industry evolution and structure (pp. 15-52). New York: Oxford University Press.

Stinchcombe, A. L. (1965). Social structure and organizations. In J. G. March (Ed.), Handbook of Organizations (pp. 142-193). Chicago: Rand McNally.

Tsui, A. S., Pearce, J. L., Porter, L. W., \& Tripoli, A. M. (1997). Alternative approaches to the employeeorganization relationship: does investment in employees pay off? Academy of Management Journal, 40, 1089-1121.

Van de Ven, A. H. (1986). Central problems in the management of innovation. Management Science, 32, $591-607$.

Waller, M. J. (1999). The timing of adaptive group responses to nonroutine events. Academy of Management Journal, 42, 127-137.

Weick, K. E. (1988). Enacted sensemaking in crisis situations. Journal of Management Studies, 25, $305-317$.

Weick, K. E., \& Roberts, K. H. (1993). Collective mind in organizations: heedful interrelating on flight decks. Administrative Science Quarterly, 38, 357-381.

Weick, K. E., \& Sutcliffe, K. M. (2001). Managing the unexpected: Assuring high performance in an age of complexity. San Francisco: Jossey-Bass.

Weick, K. E., Sutcliffe, K. M., \& Obstfeld, D. (1999). Organizing for high reliability: processes of collective mindfulness. In B. M. Staw, \& L. L. Cummings (Eds.), Research in organizational behavior (Vol. 21, pp. 81-123). Greenwich, CT: JAI Press.

Welbourne, T. M., \& Andrews, A. O. (1996). Predicting the performance of initial public offerings: should human resource management be in the equation? Academy of Management Journal, 39, 891-919.

Welbourne, T. M., \& Cyr, L. A. (1999). The human resource executive effect in initial public offering firms. Academy of Management Journal, 42, 616-629.

Wilbon, A. D. (1999). An empirical investigation of technology strategy in computer software initial public offering firms. Journal of Engineering and Technology Management, 16, 147-169.

Wildavsky, A. (1988). Searching for safety. New Brunswick, NJ: Transition.

Wright, P. M., \& Snell, S. A. (1998). Toward a unifying framework for exploring fit and flexibility in strategic human resource management. Academy of Management Review, 23(4), 756-772. 